\title{
Enhanced Screening for Hepatitis D in the USA: Overcoming the Delta Blues
}

\author{
Norah A. Terrault ${ }^{1} \cdot$ Marc G. Ghany ${ }^{2}$ \\ Published online: 5 September 2020 \\ (c) Springer Science+Business Media, LLC, part of Springer Nature 2020
}

Hepatitis D virus (HDV), the causative agent of delta hepatitis, coinfects patients infected with HBV. HDV is well recognized as the most aggressive form of viral hepatitis, with more rapid progression to cirrhosis, and a high incidence of decompensated liver disease, hepatocellular carcinoma, and liver-related death. Indeed, HDV is estimated to contribute to 1 in 6 cases of cirrhosis and 1 in 5 cases of liver cancer among persons with chronic hepatitis B globally [1]. With new therapies for HDV on the horizon [2], it is timely to look at disease burden and how effectively HDV carriers are identified.

The global prevalence of HDV was the focus of three recently published systematic reviews $[1,3,4]$, with estimates varying from a low of 12 million to as high as 72 million persons. These widely variable results highlight the challenges of estimating the global burden of HDV infection due to the paucity of seroprevalence studies in many countries, inclusion of selective populations, and use of older enzyme immunoassays that may have reduced reliability across different HDV genotypes. The seroprevalence of HDV among HBsAg-positive persons in the USA was estimated to be $5.9 \%$ (95\% CI 3.0-9.8\%) [1], but the metanalyses highlighted that US data were sparse. A recent analysis of the 2011-2016 National Health and Nutrition Examination Survey (NHANES), which is representative of the noninstitutionalized U.S. civilian population, reported an anti-HDV prevalence of $42 \%$ among hepatitis B surface antigen positive carriers [5], a rate that was substantially higher than previous estimates from NHANES covering

Norah A. Terrault

Terrault@usc.edu

1 Keck Medicine at University of Southern California, 1450 San Pablo St, HC4, Room 3056, Los Angeles, CA 90033 , USA

2 Liver Diseases Branch, National Institute of Diabetes and Digestive and Kidney Diseases, National Institutes of Health, Bethesda, MD, USA the period 1999-2012 [6]. While a true increase in HDV seroprevalence in the USA is possible, other explanations include assay variability and differences in patient sampling. Of note, the DiaSorin anti-HDV ELISA assay has lower specificity in comparison with the quantitative microarray antibody capture (QMAX) assay [7].

Based on current epidemiologic data, the American Association for the Study of Liver Diseases (AASLD) guidance on hepatitis B recommends risk-based screening for HDV. The "at risk" groups include persons who inject illicit drugs, persons with HIV, men who have sex with men, those at risk for sexually transmitted diseases, and persons who emigrated from countries of high endemicity [8]. The importance of country of origin as a risk factor for HDV in the USA is underscored by the study from Fong and colleagues from the University of Southern California published in this issue of Digestive Diseases and Sciences [9]. Among 534 Mongol immigrants and their families who participated in three community screening events conducted in 2018, 9.7\% were HBsAg positive, and among these individuals, $41 \%$ were anti-HDV positive, one-third of whom were HDV RNA positive. Interestingly, no anti-HDV-positive persons were identified under the age of 28 years, suggesting that risk factors unique to early adulthood may contribute to HDV transmission in Mongolia. Alternatively, it may reflect implementation of universal hepatitis B vaccination program in 1991, since vaccination against $\mathrm{HBV}$ remains the cornerstone of preventing HDV infection. Thus, in the USA, increased penetrance of HBV vaccination among adults at risk for HDV (e.g., HIV-positive persons who inject drugs, and those with sexually transmitted diseases) would be expected to decrease HDV seroprevalence over time, as has been shown in some European countries [10]. The study from Fong and colleagues also emphasizes the importance of education and linkage to care among immigrant populations, which they provided in the context of their screening initiative.

The recommendation to screen based on country of origin was a new addition to the 2018 AASLD guidance on 
Table 1 Current state of HDV screening

\begin{tabular}{|c|c|c|}
\hline HDV screening considerations & Challenges & Potential solutions \\
\hline Who is screened & $\begin{array}{l}\text { Screening based on country of origin requires high- } \\
\text { quality epidemiological studies (lacking in many } \\
\text { countries) and knowledge of these by a clinician } \\
\text { Lack of clinician awareness of importance of HDV } \\
\text { screening }\end{array}$ & $\begin{array}{l}\text { Universal screening of all } \mathrm{HBsAg}+\text { persons } \\
\text { Broader educational initiatives to bolster patient and } \\
\text { provider awareness }\end{array}$ \\
\hline Screening approaches & $\begin{array}{l}\text { Anti-HDV is screening test of choice, with HDV RNA } \\
\text { recommended if anti-HDV positive }\end{array}$ & $\begin{array}{l}\text { Reflex testing for anti-HDV in persons at time of first } \\
\text { HBsAg-positive result may increase completeness } \\
\text { of testing } \\
\text { Reflex HDV RNA testing of those with anti-HDV to } \\
\text { streamline the identification of those with active } \\
\text { infection }\end{array}$ \\
\hline Screening tests & $\begin{array}{l}\text { ELISA may not be equally reliable across all genotype/ } \\
\text { subtypes-more comparative work is needed } \\
\text { HDV RNA testing is not validated but based on WHO } \\
\text { standard }\end{array}$ & $\begin{array}{l}\text { QMAX may offer advantages over ELISA testing; this } \\
\text { needs to be evaluated in a large USA-based cohort } \\
\text { Studies comparing HDV RNA quantitative assays in } \\
\text { terms of LLOQ and range would be desirable }\end{array}$ \\
\hline
\end{tabular}

ELISA enzyme-linked immunoassay, $L L O Q$ lower level of quantitation

chronic hepatitis B and is supported by the current study [8]. It is acknowledged that not all healthcare providers will be familiar with the countries that have a high prevalence of HDV and thus unknowingly not offer screening to a foreignborn individual at risk. The AASLD guidance on screening highlights this limitation and suggests that if "uncertain," to just proceed with screening. Moreover, it is apparent from the recent attempts to estimate global burden of HDV that since many countries lack data of sufficient quality on HDV seroprevalence, the list of countries with high prevalence is incomplete.

Having accurate USA seroprevalence data are crucial to making recommendations on public health policy such as screening and improving the cascade of care for those with HDV, including access to new therapies as they become available. How to better obtain estimates of HDV disease burden in the USA? (Table 1) First is by making HDV a disease reportable to the Centers for Disease Control and Prevention (CDC) in order to provide a mechanism for evaluating trends in seroprevalence over time. Second is understanding how currently used assays perform among the HDV population of the USA, especially as it relates to different genotypes. Third is by considering changes to current screening practices. Given the challenges of using riskbased screening, universal screening of all $\mathrm{HBsAg}$-positive persons may be a reasonable alternative. The guidelines from the European and Asian-Pacific Associations for the Study of the Liver for management of chronic hepatitis B, recommend $\mathrm{HCV}$ and $\mathrm{HDV}$ testing in all $\mathrm{HBsAg}$-positive patients. Finally, reflex testing for anti-HDV in any patient testing positive for HBsAg may be a strategy that further increases HDV screening rates, as shown in a study from the UK [11]. Collectively, high-quality seroprevalence data would be an aid to understanding the relative contribution of different risk groups to total HDV disease burden and further facilitate next steps in the cascade of care.

The time is right for expanding on HDV screening efforts. New therapies, anticipated within the next few years, will likely be "game-changers" for this orphan disease. Currently, there are no approved therapies for HDV, and although peginterferon is a recommended approach [8], efficacy is modest at best and tolerability a barrier to its use. Excitingly, three new drug classes that have emerged for treatment of HDV, including viral entry inhibitors (Myrcludex), prenylation inhibitors (Lonafarnib), and virion egress inhibitors (REP-2139), appear very promising [2]. With the prospect of being able to change the course of this often devastating disease, it is imperative that healthcare providers not miss the diagnosis of HDV and the opportunity to limit liverrelated complications.

Acknowledgments NT discloses institutional Grant support from Gilead Sciences and Roche/Genetech.

\section{Compliance with Ethical Standards}

Conflict of interest MG has nothing to disclose.

\section{References}

1. Stockdale AJ, Kreuels B, Henrion MYR, et al. The global prevalence of hepatitis D virus infection: Systematic review and metaanalysis. J Hepatol 2020.

2. Asselah T, Loureiro D, Tout I, et al. Future treatments for hepatitis delta virus infection. Liver Int. 2020;40:54-60.

3. Chen HY, Shen DT, Ji DZ, et al. Prevalence and burden of hepatitis $\mathrm{D}$ virus infection in the global population: a systematic review and meta-analysis. Gut. 2019;68:512-521. 
4. Miao Z, Zhang S, Ou X, et al. Estimating the global prevalence, disease progression, and clinical outcome of hepatitis delta virus infection. J Infect Dis. 2020;221:1677-1687.

5. Patel EU, Thio CL, Boon D, et al. Prevalence of hepatitis B and hepatitis D virus infections in the United States, 2011-2016. Clin Infect Dis. 2019;69:709-712.

6. Njei B, Do A, Lim JK. Prevalence of hepatitis delta infection in the United States: National Health and Nutrition Examination Survey, 1999-2012. Hepatology. 2016;64:681-682.

7. Chen X, Oidovsambuu O, Liu P, et al. A novel quantitative microarray antibody capture assay identifies an extremely high hepatitis delta virus prevalence among hepatitis B virus-infected mongolians. Hepatology. 2017;66:1739-1749.

8. Terrault NA, Lok AS, McMahon BJ, et al. Update on prevention, diagnosis, and treatment and of chronic hepatitis B: AASLD 2018 hepatitis B guidance. Hepatology. 2018;67:1560-1599.
9. Fong T, Lee B, Chang M, et al. High prevalence of chronic viral hepatitis and liver fibrosis among Mongols in Southern California. Dig Dis Sci. (Epub ahead of print). https://doi.org/10.1007/s1062 0-020-06499-6.

10. Hernandez-Evole H, Briz-Redon A, Berenguer M. Changing delta hepatitis patient profile: a single center experience in Valencia region, Spain. World J Hepatol. 2020;12:277-287.

11. El Bouzidi K, Elamin W, Kranzer K, et al. Hepatitis delta virus testing, epidemiology and management: a multicentre cross-sectional study of patients in London. J Clin Virol. 2015;66:33-37.

Publisher's Note Springer Nature remains neutral with regard to jurisdictional claims in published maps and institutional affiliations. 